\title{
Correlates of internet use among African American older adults: Gender and age differences
}

\author{
Kun Wang*, Kefentse Kubanga \\ School of Social Work, University of Alabama, Tuscaloosa, Alabama, USA, 35401
}

\section{ARTICLE INFO \\ Received: December 18, 2020 \\ Accepted: January 18, 2021 \\ Published: February 10, 2021}

*CORRESPONDING AUTHOR

\section{Kun Wang,}

School of Social Work, University of Alabama, Box 870314, Tuscaloosa,

AL, 35401, USA.

kwang30@crimson.ua.edu

\section{CITATION}

Wang K, Kubanga K. (2020). Correlates of internet use among African American older adults: Gender and age differences. International Journal of Population Studies, 6(2):26-38.

doi: 10.18063/ijps.v6i2.1226

\section{Copyright: @2021 Wang} and Kubanga. This is an Open Access article distributed under the terms of the Creative Commons Attribution-Non Commercial 4.0 International License (http://creativecommons.org/ licenses/by-nc/4.0/), permitting all noncommercial use, distribution, and reproduction in any medium, provided the original work is properly cited.

\begin{abstract}
This study aimed to compare internet use among African American older adults by gender and age group and investigate correlates of internet use by gender and age group. A total of 1117 African American older adults aged over 50 from the 2016 Wave of the Health Retirement Study were included in the study. Sequential ordinal logistic regressions were conducted to investigate correlates of internet use among older African Americans by gender and age group. Significant gender and age differences were identified in internet use frequency. Gender differences on correlates were revealed: being old-old and limitations on activities of daily living were only associated with decreased odds of more frequent internet use among women. In addition, higher depression was only associated with reduced odds of more frequent internet use among men. Age differences on correlates indicated that education and cognition were the only two significant factors pertinent to internet use among the old-old. By contrast, for young-old adults, retirement, poverty, education, cognition, and depression were also predictive. Practitioners should consider these gender and age differences when promoting internet use among older African Americans. The results presented in this study might also inform the design of future gender- and age-tailored interventions.
\end{abstract}

Keywords: Internet use; African American older adults; Gender; Old-old

\section{Introduction}

The advent and fast development of information and communication technology (ICT) brings more potential for successful aging of older adults. Overcoming the limitations of distance and space, the use of ICT can expand older adults' social networks, provide healthcare treatments to people at home, offer easier access to more resources, and increase living standards (Berde, 2019; Harper, Wellman, and Quan-Haase, 2020). Recent studies have indicated the positive effects of the Internet among older populations (Cotten, Anderson, and McCullough, 2013; $\mathrm{Yu}, \mathrm{Wu}$, and $\mathrm{Chi}, 2020)$. Internet use among older adults has increased their social interactions, reduced social isolation and loneliness, helped to manage chronic diseases, assisted with activities of daily living (ADL) in older adults, and increased their quality of life (Harper, Wellman, and Quan-Haase, 2020; Kim, Lee, Christensen, et al., 2017; Yu, Wu, and Chi, 2020). Furthermore, through the Internet, many traditional interventions for older adults could be delivered online. Evaluation studies have confirmed the effectiveness of computerized interventions on reducing older adults' loneliness and depression, promoting healthy lifestyles, and increasing cognitive functioning (Choi, Kong, and Jung, 2012; Sriramatr, Berry, and Spence, 2014). Thus, use of the Internet is playing an increasingly important role in older adults' wellbeing. However, compared to young and middle-aged adults, internet use among older adults is still low. A recent Pew Research Center survey found that about two thirds older adults aged over 65 used the Internet, while the average number of all adults in the United States (U.S.) was 90\% (Anderson and Perrin, 2017). Therefore, it is necessary to investigate correlates of internet use among older adults and promote their adoption and use of the Internet. 


\subsection{Internet Use among Older African Americans}

In the past two decades, internet use among older adults in the U.S. has increased by 55\% (Anderson and Perrin, 2017). Despite the fast-growing number of older adults going online, African American older adults are lagging behind in the adoption and use of the Internet when compared with Whites (Choi and DiNitto, 2013; Elliot, Mooney, Douthit, et al., 2014; Yoon, Jang, Vaughan, et al., 2018). Choi and DiNitto (2013) analyzed a nationally representative sample of the U.S. Medicare beneficiaries aged over 65 from the 2011 National Health and Aging Trends Study and found that, compared to non-Hispanic Whites, African American older adults were 0.41 times less likely to use the Internet. A similar finding was reported in another large survey study using a sample of 17,704 older adults in the California Health Interview Survey, indicating that African American older adults were 0.54 times less likely to use the Internet for health information than their White peers (Yoon, Jang, Vaughan, et al., 2018).

Previous studies have indicated that the low internet adoption and use rates within the African American older adult population might be explained by the lower level of education, higher prevalence of poverty, and more health and mental health-related diseases (Carpenter and Buday, 2007; Berde, 2019; Kim, Lee, Christensen, et al., 2017; Mitchell, Chebli, Ruggiero, et al., 2019). Considering the benefits of the Internet on increasing health, mental health, and quality of life among older adults, the low adoption and use of internet resources among African American older adults may further enlarge existing health and mental health gaps. Thus, it is of great importance to increase internet adoption and use among this population.

Numerous studies have examined ICT use among older adults and investigated racial and ethnic differences. Most of these studies have included race or ethnicity as a categorical variable and compared African American older adults with other racial or ethnicity groups (Choi and DiNitto, 2013; Mitchell, Chebli, Ruggiero, et al., 2019; Yoon, Jang, Vaughan, et al., 2018). However, few studies have explored other aspects of racial or ethnic differences on ICT use, such as correlates. Studies on correlates of internet use may help researchers to identify target factors and further explore causal associations. It may also help practitioners identify problematic factors, design interventions to fix these problems or alleviate their influence, and promote the use of the Internet. African American older adults have different life experiences from older adults of other racial and ethnic groups in many ways, such as their social support networks, experience of depressive symptoms, and experience of systemic discrimination (Ayalon and Young, 2003; Peek and O’Neill, 2001; Sarkisian and Gerstel, 2004), so correlates of internet use among African American older adults may be different from other races or ethnicities. For example, a White older adult who experiences ageism may feel uncomfortable going outside and prefer to instead spend more time online. Different from their White counterparts, African American older adults may have experienced discrimination since their childhood or young adulthood, and they may consequently be more resilient. Thus, the effect of discrimination on internet use may be different between White and African American older adults. In addition, even though African Americans account for a large amount of racial or ethnic minorities, compared to the Whites, African Americans' population is small. Thus, results may be misleading for African Americans when exploring correlates without differentiating race or ethnic groups. Interventions based on these correlates to increase older African American's internet use may not be able to target and fix their real problems. Therefore, this study will focus on older African American adults and investigate correlates of internet use among this population.

\subsection{Gender Differences among Older Adults}

Gender differences in internet use among older adults are inconsistent. Some empirical evidence indicates that, compared with older women, older men are more likely to access and use the Internet (Kim, Lee, Christensen, et al., 2017; Marston, Kroll, Fink, et al., 2016). Attempts to explain such differences have included suggestions that older men may be higher in self-confidence, hold more positive attitudes toward the Internet, or simply be more adept in computer use (Chu, 2010; Hunsaker and Hargittai, 2018). However, several recent studies have failed to detect differences in internet use between men and women (Friemel, 2014; König, Seifert, and Doh, 2018) or have found that internet use was higher among older women as opposed to men (Yu, Ellison, McCammon, et al., 2016). These inconsistent findings related to gender differences in internet use indicate the necessity of further exploration involving correlates of internet use among older adults. Given the likelihood that multiple factors play a role in determining internet use prevalence among older adults, investigating correlates may provide more insight to gender differences in internet use among older African American adults.

In addition, older women experience aging differently from older men (Xie, 2003). For example, menopause and widowhood are social aging markers specific to the experience of older women (Osorio-Parraguez, 2013). Women who are in menopause may increase their use of the Internet to look for menopause consultation and other helpful information online. Considering the widely accepted longer life expectancy, relative to men, among older women and women's roles 
of caregivers, the negative effects of widowhood/widowerhood on daily life may affect widowers more than widows. A widower living alone at his home may need to spend more time to do housework and take care of himself than he did before his bereavement, which may reduce his time spent online. By contrast, a widow may need to spend more time online to gain more social interaction and support. Thus, the effects of correlates may be different between older men and women. In analyzing internet withdrawal reasons among older adults in Taiwan, Chiu and Liu (2017) found that older women were more likely to be affected by health factors than older men. Therefore, it is valuable to examine correlates of internet use among older adults by gender. Furthermore, considering that women live longer than men and, typically, there are more older women than men in study samples, results may be misleading for older men if they are not separated in analysis. Thus, in this study, we will investigate correlates among older African American men and women separately.

\subsection{Age Differences among Older Adults}

Age differences in internet use among older adults have been well confirmed by many previous studies (Anderson and Perrin, 2017; Chang, McAllister, and McCaslin, 2015). Compared with young-old adults, old-old adults were less likely to use the Internet. Meanwhile, they had higher risks of experiencing loneliness, cognitive decline, and increased functional limitations than their young-old counterparts (Cohen-Mansfield, Shmotkin, Blumstein, et al., 2013; Koo, Kõlves, and De Leo, 2017). Numerous studies have indicated the potential of internet use in reducing loneliness, depression, stimulating cognitive functioning, and promoting psychological well-being among older adults, especially old-old adults (Sims, Reed, and Carr, 2017; Fang, Chau, Wong, et al., 2018). Thus, increasing the adoption and use of the Internet among oldold adults is of great value. However, considering differences between young-old adults and old-old adults, especially those involving health and mental health conditions, correlates of internet use may be different. Internet use is complex and requires high cognitive functioning. Thus, different from young-old adults who have better cognitive functioning, developing the skills necessary to use the Internet may be more challenging for old-old adults. Therefore, it is important to investigate correlates of internet use by age groups to assist the design and implementation of age-tailored interventions to increase African American older adults' internet use.

\subsection{Current Study}

An overview of the literature has showed several research gaps in the literature involving African American older adults' internet adoption and utilization. First, most racial or ethnic disparity studies included race or ethnicity as a categorical variable and compared groups. However, very few studies focused on the African older adult group to explore correlates of the internet use among this specific population. Second, gender and age differences in internet use among older adults indicate the necessity of more studies to investigate correlates of different subgroups and conduct more tailored interventions to increase internet adoption and use. Thus, focusing on African American older adults, the present study will (1) compare internet use prevalence among older African American by gender and age group and (2) investigate correlates of internet use among African American older adults by gender and age groups.

\section{Method}

\subsection{Study Sample}

Data were drawn from the 2016 Wave of the Health and Retirement Study (HRS), the most recent available data from the pertinent archive. The HRS is a nationally representative longitudinal panel survey of U.S. individuals aged over 50 and their spouses. Questions about participants' health, family structure, retirement, subjective well-being, and lifestyles have been collected. HRS is funded by the National Institute on Aging (grant number NIA U01AG009740) and is conducted by the University of Michigan. The Institutional Review Board at the University of Michigan and the National Institution on Aging provided ethical approval for the HRS.

Two separate data files - 2016 HRS Core (Final) and RAND HRS Longitudinal File 2016 - were merged based on key values in the current study. internet use and perceived daily discrimination were obtained from the Left-Behind Questionnaire from the HRS core data. All other demographic, socioeconomic, health, and mental health variables were drawn from the RAND HRS data files. In the 2016 Wave, 20,912 adults participated in the survey. First, since the Left-Behind Questionnaire was assigned to a rotating (random) 50\% of participants who completed the enhanced faceto-face interview, 10,674 participants who were ineligible for the Left-Behind Questionnaire were removed from this study. Second, among the total eligible sample, 3882 participants who did not return or complete the questionnaire and 32 questionnaires completed by those who were not the assigned respondents were excluded from this study. Third, after 
removing participants who were not older than 50 or did not report their age, a subsample of 1117 African American older adults was included as the final analytic sample.

\subsection{Measures}

\subsubsection{Internet use}

The dependent variable, internet use, was measured by a single-item question, "How often do you use a computer for e-mail, Internet or other tasks?" Responses to this question were reversely coded as $1=$ never/not relevant, 2 $=$ not in the last month, $3=$ once a month, $4=$ several times a month, $5=$ once a week, $6=$ several times a week, and $7=$ daily.

\subsubsection{Health-related factors}

Previous studies have indicated that health-related factors, such as self-rated health, number of diseases, ADL, and instrumental ADL (IADL) are correlates of internet use among older adults (Ang, Lim, and Malhotra, 2020; Choi and DiNitto, 2013). Self-rated health was measured by a 5 -point Likert Scale $(1=$ poor, $2=$ fair, $3=$ good, 4 $=$ very good, and $5=$ excellent). Number of chronic illnesses was the sum of doctor diagnosed illnesses, including high blood pressure, diabetes, cancer, lung disease, heart condition, stroke, and arthritis, ranging from 0 to 7. Difficulties in ADL and IADL were measured by the total number of limited activities, including ADL, such as bathing, dressing, eating, getting in/out of bed, and walking across a room, and IADL, such as using a phone, using money, taking medications, shopping for groceries, and preparing for hot meals. Both difficulties in ADL and IADL ranged from 0 to 5 .

\subsubsection{Mental health-related factors}

Based on previous studies, depression, discrimination, and cognitive functioning were included as mental healthrelated factors in this study (Ang, Lim, and Malhotra, 2020; Choi and DiNitto, 2013; Choi, Kim, Chipalo, et al., 2020; Elliot, Mooney, Douthit, et al., 2014). Depression was measured by the Center for Epidemiological Studies Depression (CESD) scale (Radloff, 1977). Participants were asked to indicate whether they "felt depressed," "felt activities were efforts," "slept restless," "was happy," "felt lonely," "enjoyed life," "felt sad, and "could not get going" in much of the time during the past week $(0=$ no, $1=$ yes $)$. The items, "was happy" and "enjoyed life," were reversely recoded in this study $(0=$ yes, $1=$ no). Depression was assessed by the unweighted sum of the 8 binary items, ranging from 0 to 8 , with higher score indicating higher levels of depression. Perceived everyday discrimination was measured by a six-item scale. Participants were asked to indicate how often they experienced the following things, "You are treated with less courtesy or respect than other people," "You receive poorer service than other people at restaurants or stores," "People act as if they think you are not smart," "People as if they are afraid of you," "You are threatened or harassed," and "You receive poorer service or treatment than other people from doctors or hospitals." Responses to these items were reversely recoded $(1=$ never, $2=$ less than once a year, $3=\mathrm{a}$ few times a year, $4=$ a few times a month, $5=$ at least once a week, and $6=$ almost every day). Perceived everyday discrimination was assessed by the average of six items, ranging from 1 to 6 , with higher scores indicating higher levels of discrimination. Cognitive functioning was measured by a reduced version of the Telephone Interview for Cognitive Status (TIC) scale (Brandt, Spencer, and Folstein, 1988). Cognitive functioning is a composite score of immediate (0-10) and delayed word recall (0-10), serial 7s (0-5), backwards counting (0-2), date naming (month, day, year, day of week; 0-4), object naming (scissors and cactus; 0-2), naming the President (0-1), and Vice President of the United States (0-1). Cognitive functioning ranged from 0 to 35 with higher scores indicating higher cognitive functioning.

\subsubsection{Socioeconomic factors}

Education, marital status, retirement status, and poverty were included as socioeconomic factors for internet use in this study (Ang, Lim, and Malhotra, 2020; Chang, McAllister, and McCaslin, 2015; Choi and DiNitto, 2013). Education was a continuous variable and measured as years of education. Marital status $(0=$ divorced, widowed, never married, or others, $1=$ married or partnered $)$, retirement status $(0=$ not retired or partially retired, $1=$ completely retired $)$, and living in poverty $(0=$ no, $1=$ yes $)$ were measured dichotomously. 


\subsubsection{Demographic factors}

Previous studies have found that age, gender, and living arrangements were important correlates of internet use among older adults (Ang, Lim, and Malhotra, 2020; Chang, McAllister, and McCaslin, 2015; Choi and DiNitto, 2013; Choi, Kim, Chipalo, et al., 2020; Elliot, Mooney, Douthit, et al., 2014). The Pew Research Center Survey indicated that internet use among older adults dropped dramatically around 75 years of age (Anderson and Perrin, 2017). Consequently, in this study, age was categorized into a binary variable $(0<75$ years, young-old; $1=75$ years or older, old-old $)$. Gender $(0=$ men, $1=$ women $)$ and living arrangements $(0=$ living alone, $1=$ living with others $)$ were dichotomous variables.

\subsection{Analytic Strategies}

First, descriptive statistics were used to better understand the characteristics of the African American older adults in this study and their internet use status. Next, bivariate analysis of internet use was conducted to investigate gender and age differences in internet use. Third, considering that the dependent variable, internet use, was measured as an ordinal variable, ordinal logistic regressions were performed in this study. Two sets of sequential ordinal logistic regressions were conducted separately by gender and age. Four models were performed for both sets: in Model 1, only demographic factors were added; in Model 2, both demographic and socioeconomic factors were included; in Model 3, demographic, socioeconomic, and health-related factors were assessed; in Model 4, demographic, socioeconomic, health-related, and mental health-related factors were analyzed. All analyses were performed using Stata 14.2.

\section{Results}

\subsection{Sample Characteristics}

Table 1 shows descriptive characteristics of the African American older adults in the study sample. About $18 \%$ of the sample was aged 75 years or older, $63 \%$ were women and about $29 \%$ were living alone. The participants had about 13 years of education on average ( $\mathrm{SD}=2.73$ ), or just above high school completion. Less than half of the participants were married/partnered (45\%) or retired (46\%), and about $22 \%$ were living in poverty. As for their health, the mean self-rated health was $3(\mathrm{SD}=0.99)$, and on average participants had 2 chronic illness $(\mathrm{SD}=1.39)$. Participants had very low difficulties in ADL $(\mathrm{M}=0.41, \mathrm{SD}=0.98)$ and IADL $(\mathrm{M}=0.27, \mathrm{SD}=0.77)$. Regarding mental health-related factors, African American older adults had relatively low levels of depression $(\mathrm{M}=1.68, \mathrm{SD}=2.00)$ and perceived

Table 1. Sample characteristics of African American Older adults $(n=1117)$.

\begin{tabular}{|c|c|c|c|c|}
\hline & Mean & SD & $n$ & $\%$ \\
\hline \multicolumn{5}{|l|}{ Demographic } \\
\hline Old-old & & & 200 & 17.9 \\
\hline Women & & & 707 & 63.3 \\
\hline Living alone & & & 327 & 29.3 \\
\hline \multicolumn{5}{|l|}{ Socioeconomic } \\
\hline Years of education $(0-17)$ & 12.84 & 2.728 & & \\
\hline Married or partnered & & & 506 & 45.3 \\
\hline Retired & & & 509 & 45.6 \\
\hline Living in poverty & & & 242 & 21.7 \\
\hline \multicolumn{5}{|l|}{ Health-related } \\
\hline Self-rated health (1-5) & 2.94 & 0.994 & & \\
\hline Number of chronic illness $(0-7)$ & 2.19 & 1.390 & & \\
\hline Difficulties in activities of daily living (0-5) & 0.41 & 0.981 & & \\
\hline Difficulties in instrumental activities of daily living $(0-5)$ & 0.27 & 0.767 & & \\
\hline \multicolumn{5}{|l|}{ Mental health-related } \\
\hline Depression $(0-8)$ & 1.68 & 2.003 & & \\
\hline Discrimination (1-6) & 1.75 & 0.838 & & \\
\hline Cognitive functioning (0-35) & 20.28 & 4.613 & & \\
\hline
\end{tabular}


daily discrimination $(\mathrm{M}=1.75, \mathrm{SD}=0.83)$. Cognitive functioning scores among participants was about $20(\mathrm{SD}=4.61)$, indicating no cognitive impairment.

\subsection{Internet Use Differences by Gender and Age Group}

Descriptive and bivariate analyses of internet use are presented in Table 2. About 56\% of older African American adults in the study sample used the Internet at least once a week, whereas about $31 \%$ never used the Internet or reported "not relevant." Chi-square tests showed significant gender differences in internet use $\left(\chi^{2}=13.05, P<0.05\right)$. About $42 \%$ of sampled older women used the Internet daily, and $28 \%$ never used the Internet or reported "not relevant." By contrast, about $38 \%$ of older men used the Internet daily, and $37 \%$ never used the Internet or reported "not relevant." Significant age differences were also found $\left(\chi^{2}=94.82, P<0.001\right)$. Among sampled old-old adults, about $16 \%$ used the Internet daily, and $59 \%$ never used the Internet or reported "not relevant." However, among young-old adults, about $45 \%$ used the Internet daily, and 25\% never used the Internet or reported "not relevant."

\subsection{Sequential Ordinal Logistic Regression on Internet Use}

Findings from the sequential ordinal logistic regressions by gender are summarized in Table 3. In Model 1, being old-old was associated with decreased odds of more frequent use of the Internet for both men and women, while living alone was only associated with decreased odds of more frequent internet use among older men. In Model 2, more years of education was associated with increased odds of more frequent internet use for both older men and women, whereas being retired and living in poverty were associated with decreased odds of more frequent internet use for both older men and women. Age and living alone were not significant covariates among older men, while age was still significant among older women. In Model 3, more difficulties in ADL were associated with decreased odds of more frequent internet use among older women. None of the health-related factors were significant among older men. Other significant demographic and socioeconomic variables retained the same directions as in the prior model. In Model 4, better cognitive functioning was associated with increased odds of more frequent internet use both among older men and women. Depression was a significant predictor only among older men. To be more specific, for one-unit increase in the level of depression, the odds of having more frequent internet use would decrease by $23 \%$. All other significant variables in Model 3 remained significant or marginally significant

Ordinal logistic regression results by age groups were presented in Table 4. In Model 1, only among young-old adults, being women were associated with higher odds of more frequent internet use, and living alone was associated with lower odds. In Model 2, more years of education were associated with increased odds of more frequent internet use among both young-old and old-old adults. Being retired and living in poverty were associated with decreased odds and being women were associated with increased odds among young-old adults. In Model 3, no health-related factors were significant both among young-old and old-old adults. Significant variables in Model 2 remained the same direction in Model 3. In Model 4, better cognitive functioning was associated with increased odds of more frequent use of the Internet for both young- and old-old adults. Among young-old adults, depression was also a significant predictor. For a one-unit increase in the level of depression, the odds of more frequent use of the Internet would decrease by $13 \%$. All other significant variables remained the same directions as in Model 3.

Table 2. Descriptive and bivariate analysis of the internet use by gender and age group.

\begin{tabular}{|c|c|c|c|c|c|c|}
\hline \multirow[t]{3}{*}{ Internet use } & \multicolumn{2}{|c|}{ Total } & \multirow{2}{*}{$\begin{array}{c}\text { Men } \\
\%\end{array}$} & \multirow{2}{*}{$\begin{array}{c}\text { Women } \\
\%\end{array}$} & \multirow{2}{*}{$\begin{array}{c}\text { Young-old } \\
\%\end{array}$} & \multirow{2}{*}{$\begin{array}{c}\text { Old-old } \\
\%\end{array}$} \\
\hline & $\mathbf{N}$ & $\%$ & & & & \\
\hline & & & \multicolumn{2}{|c|}{$\chi^{2}=13.05 *$} & \multicolumn{2}{|c|}{$\chi^{2}=94.82^{* * * *}$} \\
\hline Never/not relevant & 341 & 30.94 & 35.89 & 28.08 & 25.00 & 58.76 \\
\hline Not in the last month & 55 & 4.99 & 2.97 & 6.16 & 4.85 & 5.67 \\
\hline Once a month & 38 & 3.45 & 2.97 & 3.72 & 3.63 & 2.58 \\
\hline Several times a month & 56 & 5.08 & 4.21 & 5.59 & 5.51 & 3.09 \\
\hline Once a week & 38 & 3.45 & 3.47 & 3.44 & 3.52 & 3.09 \\
\hline Several times a week & 132 & 11.98 & 12.87 & 11.46 & 12.33 & 10.31 \\
\hline Daily & 442 & 40.11 & 37.62 & 41.55 & 45.15 & 16.49 \\
\hline
\end{tabular}

$* \mathrm{p}<0.05 ; * * * \mathrm{p}<0.001$. 
Table 3. Ordinal logistic regression on internet use by gender.

\begin{tabular}{|c|c|c|c|c|c|c|c|c|}
\hline & \multicolumn{2}{|c|}{ Model 1} & \multicolumn{2}{|c|}{ Model 2} & \multicolumn{2}{|c|}{ Model 3} & \multicolumn{2}{|c|}{ Model 4} \\
\hline & Men & Women & Men & Women & Men & Women & Men & Women \\
\hline \multicolumn{9}{|l|}{ Demographic } \\
\hline Living alone (ref= yes) & $0.57 *$ & 0.87 & 1.21 & 0.99 & 1.18 & 0.97 & 0.38 & 1.15 \\
\hline \multicolumn{9}{|l|}{ Socioeconomic } \\
\hline Married/partnered (ref= yes) & & & 1.52 & 0.99 & 1.61 & 0.99 & 0.76 & 1.32 \\
\hline Retired (ref= yes) & & & $0.42 * * *$ & $0.39 * * *$ & $0.44 * *$ & $0.50 * * *$ & $0.39 * *$ & $0.39 * * *$ \\
\hline Living in poverty $(\mathrm{ref}=\mathrm{yes})$ & & & $0.26 * * *$ & $0.39 * * *$ & $0.27 * * *$ & $0.42 * * *$ & $0.12 * * *$ & $0.57^{+}$ \\
\hline \multicolumn{9}{|l|}{ Health-related } \\
\hline Self-rated health & & & & & 1.14 & 1.19 & 1.12 & 1.15 \\
\hline Number of diseases & & & & & 1.07 & 0.98 & 1.05 & 1.07 \\
\hline $\begin{array}{l}\text { Difficulties in instrumental } \\
\text { activities of daily living }\end{array}$ & & & & & 0.62 & 0.93 & 0.97 & 1.18 \\
\hline \multicolumn{9}{|l|}{ Mental health-related } \\
\hline Depression & & & & & & & $0.77 *$ & 0.91 \\
\hline Discrimination & & & & & & & 1.13 & 1.18 \\
\hline Cognitive functioning & & & & & & & $1.17 * * *$ & $1.12 * * *$ \\
\hline R square & 0.022 & 0.034 & 0.115 & 0.141 & 0.125 & 0.151 & 0.212 & 0.168 \\
\hline -Log Likelihood & $575.95 * * *$ & $1038.79 * * *$ & $500.78 * * *$ & $892.61 * * *$ & $472.57 * * *$ & $841.84 * * *$ & $238.65 * * *$ & $476.83 * * *$ \\
\hline
\end{tabular}

Effect sizes stand for odds ratio. ${ }^{+} \mathrm{p}<0.10 ;{ }^{*} \mathrm{p}<0.05 ;{ }^{*} \mathrm{p}<0.01 ; * * * \mathrm{p}<0.001$.

\subsection{Sensitivity Analysis}

Sensitivity analyses were conducted and presented in Appendix Tables A1-A3. First, the outcome variable, the internet use, was analyzed as a continuous variable, and multilinear regressions were conducted (Appendix Table A1). Second, the ordinal internet use variable (1-7) was recoded into two categories: internet nonuser (1) and user (2-7), and binary logistic regressions were performed and reported in Appendix Table A2. Third, the ordinal internet use variable (1-7) was categorized into a binary variable: active internet user (5-7) versus non-active user (1-4), and its binary logistic regressions were conducted and summarized in Appendix Table A3. Results from all the three analyses remained largely the same.

\section{Discussion}

The purpose of this study was to examine internet use among African American older adults and investigate gender and age differences on correlates of internet use. Internet users among older African American adults in this study were $<70 \%$, and the active users, those who used the Internet at least once a week, was only about $55 \%$. Gender and age differences in internet use were identified in this study: older women and young-old adults had higher percentages of active internet users and lower percentages of non-users than older men and old-old adults, respectively. Gender and age differences on the correlates of internet use among older African Americans were revealed: being old-old and difficulties in ADL were significant factors only for older women, whereas depression was predictive only for older men. Education and cognition were the only two significant predictors for old-old adults. By contrast, for young-old adults, besides education and cognition, being retired, living in poverty, and depression all affected their internet use.

Findings in this study indicated that membership within the old-old category was associated with decreased odds of more frequent use of the Internet only among older African American women but not men. This difference may be explained by gender differences on internalized ageist stereotypes. Compared to older men, older women are more susceptible to internalized ageist stereotypes and are more likely to feel helpless, dependent, and weak and have reduced self-esteem and self-efficacy because of their older age (Chrisler, Barney, and Palatino, 2016; Choi, Kim, Chipalo, et al., 2020). Due to the negative effects of internalized ageist stereotypes, older women may have lower self-confidence and believe that they are not capable of using the Internet when they become older, especially when they have functional 
Table 4. Ordinal logistic regression on internet use by age group.

\begin{tabular}{|c|c|c|c|c|c|c|c|c|}
\hline & \multicolumn{2}{|c|}{ Model 1} & \multicolumn{2}{|c|}{ Model 2} & \multicolumn{2}{|c|}{ Model 3} & \multicolumn{2}{|c|}{ Model 4} \\
\hline & Young-old & Old-old & Young-old & Old-old & Young-old & Old-old & Young-old & Old-old \\
\hline \multicolumn{9}{|l|}{ Demographic } \\
\hline Women & $1.38^{*}$ & 0.94 & $1.47 * *$ & 0.92 & $1.50^{* *}$ & 1.14 & $2.19 * *$ & 1.05 \\
\hline Living alone & $0.73 *$ & 0.90 & 0.98 & 1.11 & 0.99 & 0.98 & 0.91 & 0.91 \\
\hline \multicolumn{9}{|l|}{ Socioeconomic } \\
\hline Years of education & & & $1.38 * * *$ & $1.35 * * *$ & $1.37^{* * *}$ & $1.38 * * *$ & $1.22 * * *$ & $1.26^{* *}$ \\
\hline Married or partnered & & & 1.03 & 1.76 & 1.02 & 2.18 & 1.15 & 1.71 \\
\hline Retired & & & $0.38 * * *$ & 0.48 & $0.46^{* * *}$ & 0.61 & $0.37 * * *$ & 0.45 \\
\hline Living in poverty & & & $0.32 * * *$ & 0.51 & $0.32 * * *$ & 0.66 & $0.27 * * *$ & 0.75 \\
\hline \multicolumn{9}{|l|}{ Health-related } \\
\hline Self-rated health & & & & & 1.15 & 1.18 & 1.11 & 1.21 \\
\hline Number of diseases & & & & & 1.00 & 1.21 & 1.03 & 1.32 \\
\hline $\begin{array}{l}\text { Difficulties in activities } \\
\text { of daily living }\end{array}$ & & & & & 0.89 & 0.78 & 0.77 & 0.76 \\
\hline $\begin{array}{l}\text { Difficulties in } \\
\text { instrumental activities } \\
\text { of daily living }\end{array}$ & & & & & 0.81 & 0.86 & 1.15 & 1.05 \\
\hline \multicolumn{9}{|l|}{ Mental health-related } \\
\hline Depression & & & & & & & $0.87 *$ & 0.90 \\
\hline Discrimination & & & & & & & 1.19 & 1.02 \\
\hline Cognitive functioning & & & & & & & $1.15^{* * *}$ & $1.14 * *$ \\
\hline $\mathrm{R}$ square & 0.004 & 0.000 & 0.111 & 0.081 & 0.118 & 0.097 & 0.156 & 0.124 \\
\hline -Log likelihood & $1364.58 * * *$ & $255.20 * * *$ & $1165.23 * * *$ & $233.20 * * *$ & $1102.75^{* * *}$ & $217.71 * * *$ & $526.80 * * *$ & $194.56^{* * *}$ \\
\hline
\end{tabular}

Effect sizes stand for odds ratio. ${ }^{*} \mathrm{p}<0.05 ;{ }^{*} \mathrm{p}<0.01 ; * * \mathrm{p}<0.001$.

difficulties. They may be more likely to interpret their limitations in ADL as results of older age, internalize ageist stereotypes and believe that they are too old, and act out those stereotypes in the form of a self-fulfilling prophecy (Chrisler, Barney, and Palatino, 2016). Consequently, they might reduce the use of the Internet, which is consistent with a recent study (Choi, Kim, Chipalo, et al., 2020). Choi et al. (2020) also used the 2016 Wave of the HRS data and found that negative self-perception of aging was associated with reduced internet use only among older women but not older men, despite using a different analytical method.

Previous studies have indicated that older adults with depressive symptoms were more likely to have less social resources, such as living alone, lacking or having lost close relationships, and having low levels of social support, so they might be more likely to use the Internet and look for social interactions with others online (Bessiere, Kiesler, Kraut, et al., 2008; Choi and DiNitto, 2013). However, in this study, depression was found to be associated with decreased odds of more frequent use of the Internet among older African American men and not significant among women. This may be explained by different influences of depression on older men and women and their different coping strategies. The negative effects of depression on daily functioning such as decreased primary activity, mobility, and the ability to conduct household chores are more severe for men than for women (Forlani, Morri, Ferrari, et al., 2014). Older men who are affected by depression may not have time or be competent to use the Internet. Older women's internet use may also be affected by depression, but they may have been more likely to use the Internet to seek social support compared to men (Girgus, Yang, and Ferri, 2017). For example, older women experiencing depression might be more likely to chat with their families and friends online, post their experiences and feelings in their social media accounts, or look for more coping strategies online.

Age difference on correlates of internet use was also revealed in this study. Among old-old adults, those who aged 75 or older, more years of education and better cognitive functioning were the only two significant correlates of more frequent use of the Internet. However, among young-old adults, being retired, living in poverty, and depression were also predictive of internet use frequency besides education and cognition. Different from retirement, poverty, and depression, education and cognition are relevant to one's capacity to use the Internet. It seemed that compared to young-old adults, the capacity to use the Internet may be more essential for internet use among old-old adults. This could be explained by the complexity of the Internet and the required technology knowledge and skills to use it. Older adults with higher education 
may have previous training, use experience, or have more self-confidence and capacity to use the Internet (Carpenter and Buday, 2007; Choi and DiNitto, 2013; Elliot, Mooney, Douthit, et al., 2014; Hung, Lyons, and Wu, 2020). Cognitive function decreases with age, so compared to young-old adults, old-old adults may have lower cognitive functioning or even cognitive impairment, which may be the biggest challenge for them to use the Internet (Choi and DiNitto, 2013; Elliot, Mooney, Douthit, et al., 2014; Hunsaker and Hargittai, 2018).

\subsection{Limitations}

This study has several limitations. First, the cross-sectional design of this study does not allow for the estimation of causal associations. Future longitudinal studies are needed to further examine the causal predictors of technology use among older African Americans. Second, due to the limitation of the archival questionnaires, in this study, internet use was measured as use frequency by a single question. Future studies may include more computer/internet use information, such as types of activities, time spent online, and internet use efficiency (Berde, 2019). Third, this study revealed gender and age differences of internet use correlates among older African Americans. However, the mechanisms of these differences were still unclear. Future research should further investigate why some correlates were different between gender and age groups. Finally, the non-response rate of the 2016 Wave of HRS was high, nearly $40 \%$ for the entire sample and $47 \%$ for African Americans. As the non-response pattern among African Americans was related to men, living alone, and better ADL and IADL functioning, there may exist possible biases for the present findings. More research is clearly warranted to quantify such biases.

\subsection{Implications}

Despite the limitations, the current study contributes to the field of older African American' technology use in the following ways. First, this study is among the few studies focusing specifically on correlates of the technology use among older African Americans, and as such it provides more insights about this population and expands the currently limited literature. Second, this study provides valuable insights for future practice. Future interventions to promote computer/internet use among older African Americans need to target those with low socioeconomic status. Providing more computers in senior centers and more free training programs may be good ways to increase computer/internet use in this population. Furthermore, gender differences on correlates of internet use indicate that future interventions for promoting technology use among African American older adults need to be gender-tailored. For example, interventions for older African American women may need to target those at older ages and with difficulties in ADL, change their internalized negative ageist stereotypes, and empower them, whereas interventions for older men need to target those having depressive symptoms. Considering the age differences on the correlates and that the use of the Internet itself is a cognitive stimulation activity, more innovative computer training programs need to be designed to assist in the cognitive stimulation of older African Americans with and without mild cognitive impairment.

\section{Conclusions}

Literature on the use of technology by older adults is vast, but studies focusing specifically on African American older adults are very sparse and discrepant in their results. Findings in this study indicated that internet use among older African Americans is low. Interventions that integrate the use of technology would go a long way in benefiting African American older adults. Results showed similarities and gender and age differences among older African American adults. As such, practitioners should consider these gender and age differences when promoting computer/internet use among older African Americans, as well as in the design and implementation of more gender-specific interventions.

\section{Conflicts of Interest}

No conflicts of interest were reported by all others.

\section{Funding}

This study was not supported by any grant. Thank Alexandra Marbut for providing grammar checking.

\section{Authors' Contributions}

$\mathrm{KW}$ conceived the research question, conducted the analysis, drafted the introduction, methods, results, and discussions of the manuscript, and reviewed the manuscript. KK advised on the research question, drafter the introduction, and reviewed the manuscript. 


\section{Ethics Statement}

The HRS data used in this study are publicly available and are waived from the oversee of the authors' Institutional Review Board.

\section{References}

Anderson M and Perrin A. (2017). Technology use among seniors, washington, dc: Pew research center for internet \& technology. Available from: https://www.pewresearch.org/internet/2017/05/17/technology-use-among-seniors. [Last accessed on 2020 Nov 20].

Ang S, Lim E and Malhotra R. (2020). Health-related difficulty in internet use among older adults: Correlates and mediation of its association with quality of life through social support networks. Gerontologist, gnaa096. https://doi.org/10.1093/geront/gnaa096.

Ayalon L and Young MA. (2003). A comparison of depressive symptoms in african americans and caucasian americans. Journal of Cross-Cultural Psychology, 34(1):111-24. https://doi.org/10.1177/0022022102239158.

Berde E. (2019). Digital divide and robotics divide. In: Gu D and dupre ME, editors. Encyclopedia of Gerontology and Population Aging, Cham: Springer. https://doi.org/10.1007/978-3-319-69892-2_184-1.

Bessiere K, Kiesler S and Kraut R, et al. (2008). Effects of internet use and social resources on changes in depression. Information, Community and Society, 11(1):47-70. https://doi.org/10.1080/13691180701858851.

Brandt J, Spencer M and Folstein M. (1988). The telephone interview for cognitive status. Neuropsychiatry, Neuropsychology, and Behavioral Neurology, 1(2):111-7.

Carpenter BD and Buday S. (2007). Computer use among older adults in a naturally occurring retirement community. Computers in Human Behavior, 23(6):3012-24. https://doi.org/10.1016/j.chb.2006.08.015.

Chang J, McAllister C and McCaslin R. (2015). Correlates of, and barriers to, internet use among older adults. Journal of Gerontological Social Work, 58(1):66-85. https://doi.org/10.1080/01634372.2014.913754.

Chiu CJ and Liu CW. (2017). Understanding older adult's technology adoption and withdrawal for elderly care and education: Mixed method analysis from national survey. Journal of Medical Internet Research, 19(11):e374. https://doi.org/10.2196/jmir.7401.

Choi EY, Kim Y and Chipalo E, et al. (2020). Does perceived ageism widen the digital divide? And does it vary by gender? Gerontologist, 60(7):1213-23. https://doi.org/10.1093/geront/gnaa066.

Choi M, Kong S and Jung D. (2012). Computer and internet interventions for loneliness and depression in older adults: A meta-analysis. Healthcare Informatics Research, 18(3):191-8. https://doi.org/10.4258/hir.2012.18.3.191.

Choi NG and DiNitto DM. (2013). Internet use among older adults: association with health needs, psychological capital, and social capital. Journal of Medical Internet Research, 15(5):e97. https://doi.org/10.2196/jmir.2333.

Chrisler JC, Barney A and Palatino B. (2016). Ageism can be hazardous to women's health: Ageism, sexism, and stereotypes of older women in the healthcare system. Journal of Social Issues, 72(1):86-104. https://doi.org/10.1111/josi.12157.

Chu RJ. (2010). How family support and internet self-efficacy influence the effects of e-learning among higher aged adults-analyses of gender and age differences. Computers and Education, 55(1):255-64. https://doi.org/10.1016/j.compedu.2010.01.011.

Cohen-Mansfield J, Shmotkin D and Blumstein Z, et al. (2013). The old, old-old, and the oldest old: Continuation or distinct categories? An examination of the relationship between age and changes in health, function, and wellbeing. The International Journal of Aging and Human Development, 77(1):37-57. https://doi.org/10.2190/ag.77.1.c.

Cotten SR, Anderson WA and McCullough BM. (2013). Impact of internet use on loneliness and contact with others among older adults: Cross-sectional analysis. Journal of Medical Internet Research, 15(2):e39. https://doi.org/10.2196/jmir.2306.

Elliot AJ, Mooney CJ and Douthit KZ, et al. (2014). Predictors of older adults' technology use and its relationship to depressive symptoms and well-being. Journals of Gerontology Series B: Psychological Sciences and Social Sciences, 69(5):667-77. https:// doi.org/10.1093/geronb/gbt109.

Fang Y, Chau AK and Wong A, et al. (2018). Information and communicative technology use enhances psychological well-being of older adults: The roles of age, social connectedness, and frailty status. Aging and Mental Health, 22(11):1516-24. https://doi.org /10.1080/13607863.2017.1358354. 
Forlani C, Morri M and Ferrari B, et al. (2014). Prevalence and gender differences in late-life depression: A population-based study. The American Journal of Geriatric Psychiatry, 22(4):370-80. https://doi.org/10.1016/j.jagp.2012.08.015.

Friemel TN. (2014). The digital divide has grown old: Determinants of a digital divide among seniors. New Media and Society, 18(2):313-31. https://doi.org/10.1177/1461444814538648.

Girgus JS, Yang K and Ferri CV. (2017). The gender difference in depression: Are elderly women at greater risk for depression than elderly men? Geriatrics, 2(4):35. https://doi.org/10.3390/geriatrics2040035.

Harper MG, Wellman B and Quan-Haase A. (2020). Older adults and information and communication technologies in the global north. In: Gu D and Dupre ME, editors. Encyclopedia of Gerontology and Population Aging, Cham: Springer. https://doi. org/10.1007/978-3-319-69892-2_902-1.

Hung LY, Lyons JG and Wu CH. (2020). Health information technology use among older adults in the United States, $2009-2018$. Current Medical Research and Opinion, 36(5):789-97. https://doi.org/10.1080/03007995.2020.1734782.

Hunsaker A and Hargittai E. (2018). A Review of internet use among older adults. New Media and Society, 20(10):3937-54. https://doi. org/10.1177/1461444818787348.

Kim J, Lee HY and Christensen MC, et al. (2017). Technology access and use, and their associations with social engagement among older adults: Do women and men differ? Journals of Gerontology Series B: Psychological Sciences and Social Sciences, 72(5):83645. https://doi.org/10.1093/geronb/gbw123.

König R, Seifert A and Doh M. (2018). Internet use among older europeans: An analysis based on SHARE data. Universal Access in the Information Society, 17(3):621-33. https://doi.org/10.1007/s10209-018-0609-5.

Koo YW, Kõlves K and de Leo D. (2017). Suicide in older adults: Differences between the young-old, middle-old, and oldest old. International Psychogeriatrics, 29(8):1297-306. https://doi.org/10.1017/s1041610217000618.

Marston HR, Kroll M and Fink D, et al. (2016). Technology use, adoption and behavior in older adults: Results from the iStoppFalls project. Educational Gerontology, 42(6):371-87. https://doi.org/10.1080/03601277.2015.1125178.

Mitchell UA, Chebli PG and Ruggiero L, et al. (2019). The digital divide in health-related technology use: The significance of race/ ethnicity. Gerontologist, 59(1):6-14. https://doi.org/10.1093/geront/gny138.

Osorio-Parraguez PJ. (2013). Health and widowhood: Meanings and experience of elderly women in chile. Health, 5:1272-6. https:// doi.org/10.4236/health.2013.58173.

Peek MK and O'Neill GS. (2001). Networks in later life: An examination of race differences in social support networks. The International Journal of Aging and Human Development, 52(3):207-29. https://doi.org/10.2190/f1q1-jv7d-vn77-16wx.

Radloff LS. (1977). The CES-D scale: A self-report depression scale for research in the general population. Applied Psychological Measurement, 1(3):385-401. https://doi.org/10.1177/014662167700100306.

Sarkisian N and Gerstel N. (2004). Kin support among blacks and whites: Race and family organization. American Sociological Review, 69(6):812-37. https://doi.org/10.1177/000312240406900604.

Sims T, Reed AE and Carr DC. (2017). Information and communication technology use is related to higher well-being among the oldest-old. The Journals of Gerontology: Series B, 72(5):761-70. https://doi.org/10.1093/geronb/gbw130.

Sriramatr S, Berry TR and Spence JC. (2014). An internet-based intervention for promoting and maintaining physical activity: A randomized controlled trial. American Journal of Health Behavior, 38(3):430-9. https://doi.org/10.5993/ajhb.38.3.12.

Xie B. (2003). Older adults, computers, and the internet: Future directions. Gerontechnology, 2(4):289-305.

Yoon H, Jang Y and Vaughan PW, et al. (2018). Older adults' internet use for health information: Digital divide by race/ethnicity and socioeconomic status. Journal of Applied Gerontology, 39(1):105-10. https://doi.org/10.1177/0733464818770772.

$\mathrm{Yu} \mathrm{K,} \mathrm{Wu} \mathrm{S} \mathrm{and} \mathrm{Chi} \mathrm{I.} \mathrm{(2020).} \mathrm{Internet} \mathrm{use} \mathrm{and} \mathrm{loneliness} \mathrm{of} \mathrm{older} \mathrm{adults} \mathrm{over} \mathrm{time:} \mathrm{The} \mathrm{mediating} \mathrm{effect} \mathrm{of} \mathrm{social} \mathrm{contact.} \mathrm{The} \mathrm{Journals}$ of Gerontology: Series B, gbaa004. https://doi.org/10.1093/geronb/gbaa004.

Yu RP, Ellison NB and McCammon RJ, et al. (2016). Mapping the two levels of digital divide: Internet access and social network site adoption among older adults in the USA. Information, Communication and Society, 19(10):1445-64. https://doi.org/10.1080/13 69118x.2015.1109695. 


\section{Appendix}

Table A1. Multilinear regression coefficients of internet use.

\begin{tabular}{|c|c|c|c|c|}
\hline & \multicolumn{2}{|c|}{ Gender } & \multicolumn{2}{|c|}{ Age } \\
\hline & Men & Women & Old-old & Young-old \\
\hline \multicolumn{5}{|l|}{ Demographic } \\
\hline Women & & & $1.01 * *$ & 0.29 \\
\hline Old-old & -0.25 & $-1.15^{* * *}$ & & \\
\hline Living alone & -0.80 & 0.11 & -0.48 & -0.06 \\
\hline \multicolumn{5}{|l|}{ Socioeconomic } \\
\hline Years of education & $0.15 * *$ & $0.23^{* * *}$ & $0.26^{* * *}$ & $0.26 * *$ \\
\hline Married or partnered & -0.05 & 0.20 & 0.10 & 0.51 \\
\hline Retired & $-1.18 * *$ & $-0.78 * *$ & $-1.00^{* *}$ & -0.43 \\
\hline Living in poverty & $-1.95 * * *$ & $-0.68^{*}$ & $-1.10^{* *}$ & -0.52 \\
\hline \multicolumn{5}{|l|}{ Health-related } \\
\hline Self-rated health & 0.12 & 0.14 & 0.17 & 0.11 \\
\hline Number of diseases & 0.11 & 0.05 & 0.12 & 0.31 \\
\hline Difficulties in activities of daily living & -0.31 & $-0.29 *$ & -0.19 & -0.34 \\
\hline Difficulties in instrumental activities of daily living & 0.14 & 0.19 & 0.03 & 0.16 \\
\hline \multicolumn{5}{|l|}{ Mental health-related } \\
\hline Depression & $-0.21^{*}$ & -0.09 & -0.13 & -0.09 \\
\hline Discrimination & 0.18 & 0.11 & 0.19 & 0.35 \\
\hline Cognitive functioning & $0.16^{* * *}$ & $0.12 * * *$ & $0.17 * * *$ & $0.14 * *$ \\
\hline
\end{tabular}

Effect sizes stand for unstandardized coefficients. ${ }^{*} \mathrm{p}<0.05 ; * * \mathrm{p}<0.01 ;{ }^{* * *} \mathrm{p}<0.001$.

Table A2. Logistic regression odds ratios of internet use.

\begin{tabular}{|c|c|c|c|c|}
\hline & \multicolumn{2}{|c|}{ Gender } & \multicolumn{2}{|c|}{ Age Group } \\
\hline & Men & Women & Old-old & Young-old \\
\hline \multicolumn{5}{|l|}{ Demographic } \\
\hline Women & & & $2.75^{* *}$ & 1.34 \\
\hline Old-old & 0.53 & $0.31 * * *$ & & \\
\hline Living alone & 0.37 & 1.03 & 0.62 & 0.94 \\
\hline \multicolumn{5}{|l|}{ Socioeconomic } \\
\hline Years of education & $1.25^{* *}$ & $1.39 * * *$ & $1.30 * * *$ & $1.30 * *$ \\
\hline Married or partnered & 1.27 & 1.17 & 1.11 & 1.67 \\
\hline Retired & $0.32 *$ & $0.43^{*}$ & $0.37 * *$ & 0.65 \\
\hline Living in poverty & $0.15^{* *}$ & 0.66 & $0.33 * *$ & 0.60 \\
\hline \multicolumn{5}{|l|}{ Health-related } \\
\hline Self-rated health & 1.22 & 1.12 & 1.19 & 1.12 \\
\hline Number of diseases & 1.17 & 1.12 & 1.13 & $1.36^{+}$ \\
\hline Difficulties in activities of daily living & 0.94 & $0.71^{+}$ & 0.82 & 0.71 \\
\hline Difficulties in instrumental activities of daily living & 1.28 & 1.03 & 1.03 & 1.17 \\
\hline \multicolumn{5}{|l|}{ Mental health-related } \\
\hline Depression & $0.70^{* *}$ & 0.96 & 0.88 & 0.91 \\
\hline Discrimination & 1.29 & 1.27 & 1.20 & 1.42 \\
\hline Cognitive functioning & $1.22 * * *$ & $1.13^{* *}$ & $1.19 * * *$ & $1.15 * * *$ \\
\hline
\end{tabular}

Effect sizes stand for odds ratio. ${ }^{+} \mathrm{p}<0.10 ;{ }^{*} \mathrm{p}<0.05 ;{ }^{*} \mathrm{p}<0.01 ; * * * \mathrm{p}<0.001$. 
Table A3. Logistic regression odds ratios of active internet use.

\begin{tabular}{|c|c|c|c|c|}
\hline & \multicolumn{2}{|c|}{ Gender } & \multicolumn{2}{|c|}{ Age group } \\
\hline & Men & Women & Old-old & Young-old \\
\hline \multicolumn{5}{|l|}{ Demographic } \\
\hline Women & & & $1.93 *$ & 0.93 \\
\hline Old-old & 0.94 & $0.41 * *$ & & \\
\hline Living alone & 0.48 & 1.12 & 1.09 & 0.70 \\
\hline \multicolumn{5}{|l|}{ Socioeconomic } \\
\hline Years of education & $1.17 *$ & $1.24 * * *$ & $1.18 * *$ & $1.20 *$ \\
\hline Married or partnered & 0.92 & 1.54 & 1.51 & 1.32 \\
\hline Retired & $0.16^{* * *}$ & $0.59^{+}$ & $0.34 * * *$ & 0.76 \\
\hline Living in poverty & $0.04 * * *$ & $0.47^{*}$ & $0.19 * * *$ & 0.61 \\
\hline \multicolumn{5}{|l|}{ Health-related } \\
\hline Self-rated health & 1.20 & 1.11 & 1.09 & 1.22 \\
\hline Number of diseases & 1.26 & 0.92 & 1.03 & 1.23 \\
\hline Difficulties in activities of daily living & 0.75 & $0.67 *$ & $0.68^{*}$ & 0.69 \\
\hline Difficulties in instrumental activities of daily living & 0.99 & 1.28 & 1.32 & 0.99 \\
\hline \multicolumn{5}{|l|}{ Mental Health-related } \\
\hline Depression & $0.77^{+}$ & 0.91 & $0.86^{*}$ & 0.82 \\
\hline Discrimination & $1.51^{+}$ & 1.06 & 1.31 & 0.83 \\
\hline Cognitive functioning & $1.17 * *$ & $1.12 * *$ & $1.16 * * *$ & $1.12 *$ \\
\hline
\end{tabular}

The active Internet use was defined as use of the Internet at least several times per month. Effect sizes stand for odds ratio. ${ }^{+} \mathrm{p}<0.10 ;{ }^{*} \mathrm{p}<0.05 ;{ }^{* *} \mathrm{p}<0.01$; $* * * \mathrm{p}<0.001$ 